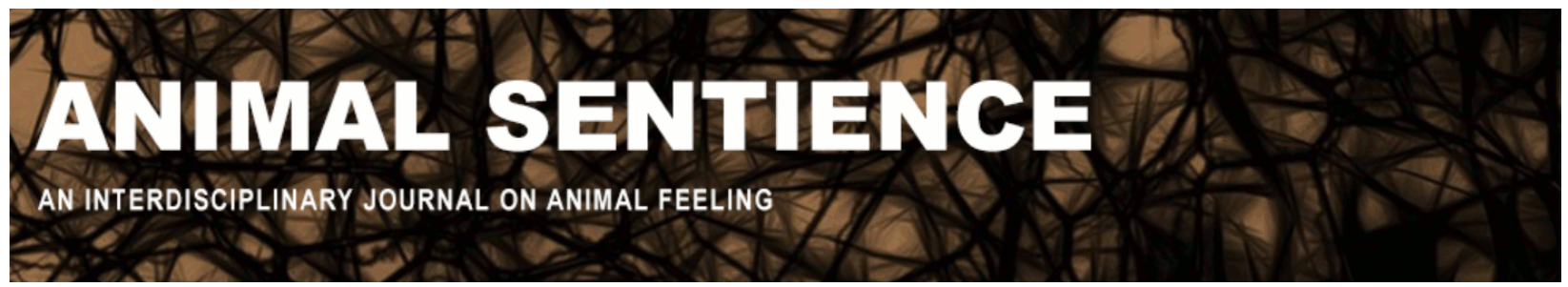

Merker, Bjorn H. (2016) How not to move the line drawn on pain. Animal Sentience 3(40)

DOI: $10.51291 / 2377-7478.1073$

Date of submission: 2015-12-19

Date of acceptance: $2015-12-28$

(c)

This article has appeared in the journal Animal

Sentience, a peer-reviewed journal on animal

cognition and feeling. It has been made open access,

free for all, by WellBeing International and deposited

in the WBI Studies Repository. For more information,

please contact

wbisr-info@wellbeingintl.org.

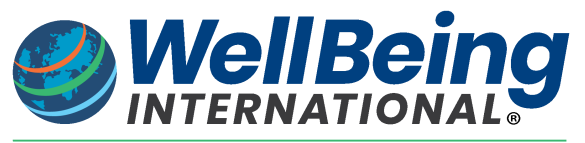

SOLUTIONS FOR PEOPLE, ANIMALS AND ENVIRONMENT 


\title{
How not to move the line drawn on pain
}

Commentary II on Key on Fish Pain

\author{
Bjorn Merker \\ Kristianstad, Sweden
}

\begin{abstract}
In this second commentary I outline the inadequacy of Key's responses to the many peer critiques of his thesis that have so far appeared in Animal Sentience. I illustrate with examples drawn from his response to my first commentary.
\end{abstract}

\begin{abstract}
Bjorn Merker gyr694c@tninet.se is a neuroscientist with longstanding interest in brain mechanisms of consciousness: He has worked on subcortical mechanisms of orienting behavior in rodents and cats, mirror self-recognition in gibbons, and

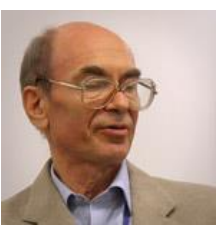
structural principles intrinsic to the neural organization of a conscious state. Fjälkestadsv. 410-82, SE-29194 Kristianstad, Sweden. https://en.wikipedia.org/wiki/Björn Merker
\end{abstract}

In his target article "Why fish do not feel pain," Key (2016) presents the thesis that fish nocifensive behavior is not attended by pain of any kind. In answering his many critics Key typically points to the various ways in which they have violated the premises on which his argument is built or have ignored the purported facts on which it relies. Such a manner of proceeding is unexceptionable when those premises and facts themselves are unexceptionable - i.e., when they represent uncontroversial and secure assumptions and facts.

Key's argument, however, is based squarely on still controversial proposals in one of the youngest and most contentious branches of neuroscience, namely, the neuroscience of consciousness. In this nascent subdiscipline, settled science is still a matter of the future. One therefore cannot, as Key does, insist on a particular structure-function conjecture when critics repeatedly point out that it is not the sole plausible and conceptually coherent option available, and that alternative readings of the evidence lead to conclusions at variance with those that Key draws. Such objections must be addressed in substantive terms, or else they stand unanswered. Yet time and time again Key simply ignores substantive objections, without so much as a word indicating that they have even been raised. Though Key's (2016a) response to my long commentary (Merker, 2016) is certainly not the only example of this, I will in the interest of brevity confine myself exclusively to that response in this commentary.

My original commentary contains two long parts. The second of these chronicles deficiencies in Key's scholarship. It covers matters ranging from numerous faulty citations to ways in which major strands of evidence on which Key relies in his exclusively corticocentric conception of human pain (lesions, gamma oscillations, information measures) fail to provide unequivocal 
support for that conception. And Key's response? None at all. Yet silence will not make these problems go away. They are there in his target article for anyone to scrutinize in the light of my own criticisms and those of many others of his peers, and until these are answered convincingly, they stand.

The equally long and detailed first section ("The argument") covers matters of principle when it comes to relating the structure of neural organization to experience, and in particular the experiences we call feelings, such as pain. It introduces a set of technical matters involving the formal prerequisites for purposive behaviors - situationally appropriate responses to unpredictable and changing external circumstances that accomplish invariant outcomes in real time - and the role of feelings in generating those invariant outcomes. Control requirements in this domain lie far beyond those of a laboriously conditioned scratch reflex - of which the isolated spinal cord is capable - and may require consciousness to be optimized. It is therefore of interest that in the case of nocifensive behavior they appear to lie within the functional capacity of a forebrainless midbrain, as outlined in my commentary. I go on to suggest that the tectal-periaqueductal complex (not "the tectum," as Key erroneously asserts) might house the circuitry through which nocifensive behavior is attended by pain, in fish as in other vertebrates.

And Key's response? He ignores my substantive arguments, but charges me with simplifying his argument to one that claims that only an animal possessing a cortex can feel pain, and he attempts to overturn my suggestion regarding the tectal-periaqueductal complex. First the matter of "cortex": I deliberately used the term "laminated pallium" instead of cortex or neocortex to signal my awareness of the pitfalls for the unwary contained in Key's studious avoidance of the term "mammalian neocortex" when he itemizes (under four points) his no less than 21 separate structure-function criteria for the very possibility of experiencing pain ("only vertebrate nervous systems possessing all of the following neuroanatomical features will be capable of feeling pain").

It is, however, patently obvious that the 21 criteria that follow are a detailed inventory of the particulars of Key's conception of the representation of pain in the mammalian (and more specifically human) neocortex. Only the mammalian neocortex actually exhibits all those features taken together. Key's studious avoidance of the term "neocortex" for what is plainly a catalogue of neocortical features is presumably motivated by his wanting to include birds among animals capable of feeling pain. Yet his categorical inclusion of "laminated organization" (under Point 2), without any qualifying clause regarding "equivalent circuitry" either there or in the sentence introducing his numbered points, clearly excludes the birds. They do have homologous circuitry, but its organization is nuclear and not laminar, so birds do not fulfill Key's criteria (unless Key thinks that birds experience pain by means of their visual Wulst, which is laminated).

Abandoning "laminated organization" for "reciprocally connected nuclei" in fact necessitates scrutiny of numerous complex constellations of reciprocally interconnected nociception-related subtelencephalic nuclear groupings for candidate pain circuitries. I accordingly recommended the tectal-periaqueductal complex for such scrutiny. This dorsal midbrain complex is typically 
the largest single brain compartment in teleosts. It provides an interface between the critical nociception/nocifensive apparatus of the periaqueductal gray and the topographic and multimodal sensory maps of surrounding space arrayed in exquisitely laminar fashion in the overlying tectum.

Key attempts to counter this suggestion by reiterating that the tectum "lacks the necessary neural architecture" (though my suggestion concerned a wider constellation than the tectum itself) and by claiming that "tectal ablation does not perturb responses to noxious stimuli." The latter claim, which in his target article is spelled out as "its ablation does not affect escape responses to either touch or electric shock (Yager et al., 1977)," involves an astonishing misreading of the cited study. Contrary to what Key claims, Yager and colleagues report that after collicular ablation visually conditioned goldfish breathing responses to electric shock are abolished, and recover only after regeneration of optic tract axons!

Key also cites Lovejoy and Krauzlis (2010) for the assertion that the primate colliculus does not contribute to conscious awareness, though there is not one word about this issue in that paper. What that paper - along with other references I cite in my original commentary - does show is that the colliculus provides a causal link in sophisticated top-down processes and is not, as Key erroneously claims, limited to bottom-up attentional functions. In other words, Key has not only failed to answer the substantive points raised in my original commentary, but in responding has added to the already long list of problems and errors detailed there. So far, then, he has not

given the slightest reason for the midbrain-hindbrain line drawn on pain in my commentary to budge.

\section{References}

Key, B. (2016). Why fish do not feel pain. Animal Sentience 2016.003.

Key, B. (2016a). Falsifying the null hypothesis that "fish do not feel pain." Animal Sentience 2016.039.

Lovejoy, L. P. and Krauzlis, R. J. (2010). Inactivation of primate superior colliculus impairs covert selection of signals for perceptual judgments. Nature Neuroscience 13, 261-267.

Merker, B. (2016). Drawing the line on pain. Animal Sentience 2016.030.

Yager, D., Sharma, S. C. and Grover, B. G. (1977). Visual function in goldfish with unilateral and bilateral tectal ablation. Brain Research 137, 267-275. 